\title{
Incidentally Detected Gastrointestinal Wall Thickness on Abdominal Computed Tomography; What Does it Mean for Endoscopy?
}

Erkan Somuncu, $\mathrm{MD}^{1 *}$; Ümmihan Topal, $\mathrm{MD}^{2}$; Süleyman Sönmez, $\mathrm{MD}^{2}$; Yasin Kara, $\mathrm{MD}^{1}$; Emre Bozdağ, $\mathrm{MD}^{1}$; Adem Özcan, $\mathrm{MD}^{1}$; Ceren Başaran, MD'; Cenk Özkan, MD'; Yunus Emre Tatıdil, MD'; Mustafa Uygar Kalaycı, MD'1

'Department of General Surgery, University of Health Sciences, Kanuni Sultan Suleyman Training and Research Hospital, Istanbul, Turkey

${ }^{2}$ Department of Radiology, University of Health Sciences, Kanuni Sultan Suleyman Training and Research Hospital, Istanbul, Turkey

\begin{abstract}
Background: The clinical significance of gastrointestinal wall thickening (GWT) on abdominal computed tomography (CT) is not certain, yet. Despite the need for clinical guidelines describing the importance and evaluation of GWT on a CT scan, there have been few studies evaluating these incidental imaging abnormalities. The aim of this study is to endoscopically evaluate certain etiologies that cause incidental GWT found on CT.

Methods: This retrospective cohort study was carried out with patients who had incidentally detected GWT on a CT scan at the Kanuni Sultan Süleyman Training and Research Hospital between February 2016 and December 2018.

Results: A total of 129 patients (62 males and 67 females; mean age 57.5 years, range: 26-87 years) were included in the study. Abnormalities observed during endoscopy at the exact site of the GWT noted on a CT image were found in 114 patients (99\%): upper endoscopy revealed malignancy in $33(29 \%)$, gastritis in $63(52 \%)$, hiatal hernia in $19(16 \%)$, a gastric ulcer in $7(6 \%)$, and alkaline gastritis in $3(2 \%)$. Colonoscopy revealed malignancy in $4(33 \%)$, benign polyps in $5(35 \%)$, colonic ulcer in $2(16 \%)$, and 2 patients $(16 \%)$ had normal findings. Malignancy was detected more frequently in the cardioesophageal region compared with the antrum $(\mathrm{P}=0.020)$.

Conclusion: In this study, detection of GWT on CT often indicated pathologies which were subsequently confirmed endoscopically. Pathological findings were detected in $83 \%$ of these patients, with approximately $30 \%$ determined to be malignant. Endoscopic evaluation is recommended when GWT is reported on a CT scan.

Keywords: Computed tomography, Endoscopy, Gastrointestinal wall thickness

Cite this article as: Somuncu E, Topal Ü, Sönmez S, Kara Y, Bozdağ E, Özcan A, et al. Incidentally detected gastrointestinal wall thickness on abdominal computed tomography; what does it mean for endoscopy?. Arch Iran Med. 2021;24(4):296-300. doi: 10.34172/aim.2021.41
\end{abstract}

Received: April 2, 2020, Accepted: December 16, 2020, ePublished: April 1, 2021

\section{Introduction}

Increased wall thickness anywhere in the gastrointestinal tract is an important finding that should not be disregarded. Increased wall thickness may have many causes; however, benign or malignant neoplasms, inflammation, and postoperative changes are the most common. Most of these can be detected by computed tomography (CT) ${ }^{1,2}$ However, CT may not be sufficient to provide the full explanation. Endoscopy is the gold standard for diagnosis in the upper and lower gastrointestinal tract. During this procedure, CT provides the endoscopist with valuable information. Wall thickening is often noted in the digestive tract during abdominal imaging in patients without gastrointestinal complaints. When this finding is encountered, the endoscopist has a significant role. A careful endoscopic examination is required to determine whether the increase in wall thickness is malignant, benign, or normal. ${ }^{3,4}$ The average wall thickness threshold in the upper and lower gastrointestinal tract is $5 \mathrm{~mm} .{ }^{5,6}$ Gastrointestinal wall thickening (GWT) is often related to antral gastritis in the stomach or noninfectious colitis in the colon. Increased wall thickness may also be caused by increased edema secondary to cirrhosis, heart failure, nephrotic syndrome, or hypoalbuminemia.?

There is currently no algorithm for an approach to be followed in the event of increased wall thickness in the gastrointestinal tract. The objective of this study was to evaluate the endoscopy findings of patients with findings of increased wall thickness in the gastrointestinal tract on CT performed for various complaints.

\section{Materials and Methods}

In this study, the records of all patients who underwent gastroscopy or colonoscopy in the general surgical endoscopy unit between February 2016 and December 2018 were retrospectively analyzed. Among these patients, 
those who had GWT, noted incidentally on CT images taken before endoscopy performed for non-specific complaints, were included in the study. Wall measurement values greater than $5 \mathrm{~mm}$ in the esophagus, stomach, duodenum, colon, or rectum were considered above average wall thickness. The demographic data and the pathology and endoscopy results of the patients included in the study were analyzed. Patients with previously known gastrointestinal system (GIS) pathology (malignancy, inflammatory bowel disease, hiatal hernia), or previous surgery, and patients with conditions that may cause GIS wall thickening, such as heart failure, cirrhosis, nephrotic syndrome, or hypoalbuminemia, were excluded. In addition, patients with small intestine wall thickness observed on imaging were excluded from the study.

All study patients were over the age of 18 . Informed consent was obtained from all participants.

\section{Statistical Analysis}

IBM SPSS Statistics for Windows, version 22.0 (IBM Corp., Armonk, NY, USA) was used to perform the statistical analysis. The patient demographic data and clinical characteristics were expressed as mean \pm SD, median, and percentage, as appropriate. Non-parametric data were evaluated using the Mann-Whitney $U$ test. Statistical significance was set at $P<0.05$.

\section{Results}

An increase in GWT was detected on the abdominal CT scan in 129 patients. In all, 62 were men and 67 were women; the median age was 58 years (range: 26-87 years). Of these patients, 116 underwent gastroscopy and 13 underwent colonoscopy.

Table 1 displays the gastroscopy and pathology findings. Thirty-five patients (29\%) had stomach cancer, 63 (52\%) had gastritis, 19 (16\%) had a hiatal hernia, 3 (2\%) had a benign gastric polyp, $7(6 \%)$ had a gastric ulcer, 3 (2\%) had alkaline reflux gastritis, 1 (0.8\%) had esophageal varices, $1(0.8 \%)$ had distal esophagitis, and 2 patients $(1 \%)$ had normal findings. Among the 116 who underwent gastroscopy, 55 were men, 61 were women, and the median age was 58.5 years (range: 26-87 years).

Table 1. Endoscopy Results of Patients with Upper Gastrointestinal Wall Thickness Detected on Computed Tomography

\begin{tabular}{lcc}
\hline Cases & No. $(\%)$ & $\begin{array}{c}\text { Male/ } \\
\text { Female }\end{array}$ \\
\hline Normal & $2(1)$ & $0 / 2$ \\
\hline Cancer & $35(29)$ & $23 / 12$ \\
Gastritis & $63(52)$ & $25 / 38$ \\
\hline Hiatal hernia & $19(16)$ & $11 / 8$ \\
\hline Benign gastric polyp & $3(2)$ & $0 / 3$ \\
\hline Gastric ulcer & $7(6)$ & $3 / 4$ \\
\hline Alkaline gastritis & $3(2)$ & $1 / 2$ \\
\hline Esophageal varices & $1(0,8)$ & $0 / 1$ \\
\hline Distal esophagitis & $1(0,8)$ & $0 / 1$ \\
\hline Positive Helicobacter pylori infection & $35(55)$ & $14 / 21$ \\
\hline
\end{tabular}

The mean age of patients with gastric cancer was $58.24 \pm$ 13.55 years. Figures 1 and 2 illustrate examples of benign and malignant stomach cases.

The colonoscopy and pathology findings are provided in Table 2. Four patients (33\%) had colorectal carcinoma, five $(33 \%)$ had benign polyps, two $(16 \%)$ had a colonic ulcer, and two patients (16\%) had normal findings. Seven were men, and six were women, with a median age of 55.75 years (range: $32-77$ years). The mean age of patients with colorectal cancer was $54.5 \pm 15.37$ years. Figures 3 and 4 show examples of benign and malignant cases of the colorectal region.

Tables 3 and 4 show the incidence of wall thickness in the parts of the stomach and colon. Abdominal CT imaging of the upper gastrointestinal tract revealed that the most common site of wall thickness was the gastric antrum, and in most cases, an endoscopic biopsy showed antral gastritis. In abdominal CT imaging of the lower

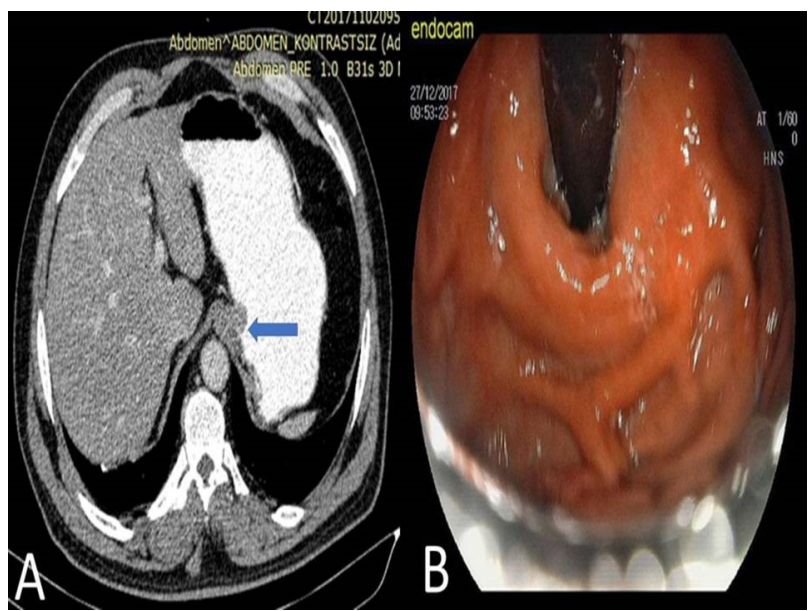

Figure 1. (A) Asymmetric wall thickening toward the stomach lumen is observed at the level of the cardioesophageal junction on an abdominal CT image (arrow). (B) Erosive pangastritis was detected on endoscopy and the endoscopic biopsy results were positive for Helicobacter pylori.

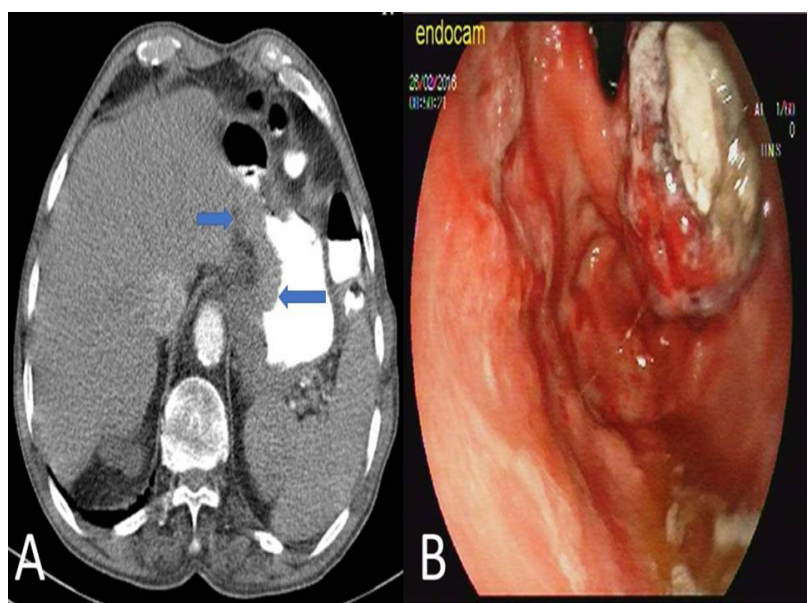

Figure 2. (A) Abdominal computed tomography image demonstrates symmetric wall thickening at the cardioesophageal junction and a small curved projection toward the lumen (arrows). (B) The endoscopy report showed cancer of the gastric cardia and adenocarcinoma was detected as a result of the biopsy. 
Table 2. Endoscopy Results of Patients with Colonic Wall Thickness Detected on Computed Tomography

\begin{tabular}{lcc}
\hline Cases & No. $(\%)$ & Male/Female \\
\hline Normal & $2(16)$ & $1 / 1$ \\
Cancer & $4(33)$ & $3 / 1$ \\
Colonic ulcer & $2(16)$ & $0 / 2$ \\
Benign colon polyps & $5(35)$ & $3 / 2$ \\
\hline
\end{tabular}

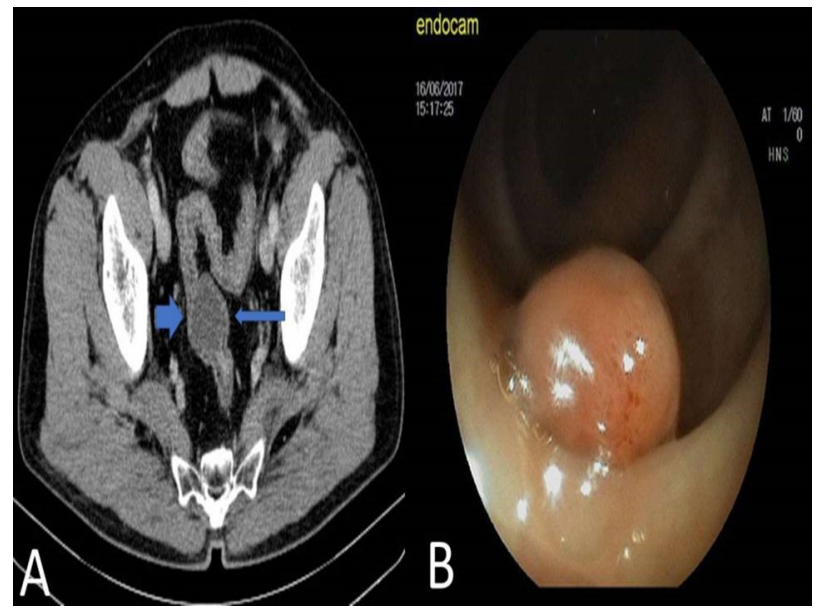

Figure 3. (A) Abdominal computed tomography image demonstrates wall thickening into the lumen distal part of the sigmoid column (arrows). (B) A polypoid formation was observed in the sigmoid colon in the endoscopy report and tubular adenoma was detected in the biopsy results of a polypectomy.

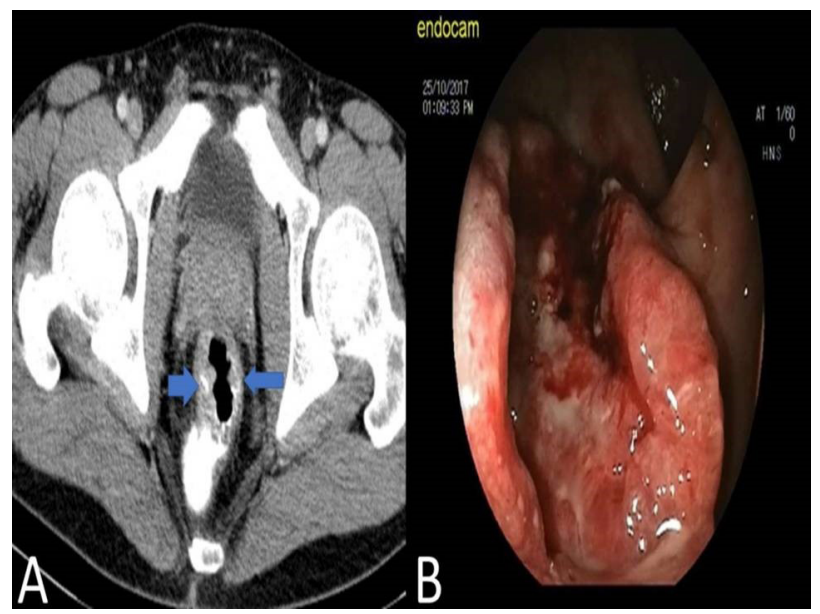

Figure 4. (A) Asymmetric circumferential wall thickening in the rectal wall is observed in an abdominal computed tomography image (arrows). (B) The endoscopy report showed an ulcerovegetative mass beginning at $5 \mathrm{~cm}$ from the anal line. Rectal adenocarcinoma was confirmed in the biopsy report.

gastrointestinal tract, the most common location of an increase in wall thickness was the rectosigmoid region.

\section{Discussion}

Findings in the upper and lower gastrointestinal tract can be best demonstrated with high-quality CT imaging using multiple thin sections. Increased wall thickness detected by CT scans may be identified for various reasons, including malignancies, benign lesions, inflammation, ischemia, inflammatory bowel disease, and postoperative changes. ${ }^{8}$

In a study in 2003, Insko et $\mathrm{al}^{9}$ detected an increase in
Table 3. Frequency of Upper Gastrointestinal Wall Thickening by Localization of Specific Abnormalities Seen During Endoscopy in Patients with Computed Tomography Findings

\begin{tabular}{lccc}
\hline Site & No. (\%) & Male/Female & $\begin{array}{c}\text { Benign/Malignant } \\
\text { Pathology }\end{array}$ \\
\hline $\begin{array}{l}\text { Cardioesophageal } \\
\text { junction }\end{array}$ & $16(14)$ & $9 / 7$ & $8 / 8$ \\
Cardia & $7(6)$ & $4 / 3$ & $3 / 4$ \\
Fundus & $1(1)$ & $1 / 0$ & $1 / 0$ \\
Corpus & $8(7)$ & $3 / 5$ & $1 / 4$ \\
Antrum & $74(63)$ & $29 / 45$ & $58 / 16$ \\
Diffuse & $10(9)$ & $7 / 3$ & $7 / 3$ \\
\hline
\end{tabular}

Table 4. Frequency of Colonic Wall Thickening by Localization of Specific Abnormalities Seen During Endoscopy in Patients with Computed Tomography Findings

\begin{tabular}{lccc}
\hline Site & No. (\%) & Male/Female & $\begin{array}{c}\text { Benign/Malignant } \\
\text { Pathology }\end{array}$ \\
\hline Rectum & $7(53)$ & $4 / 3$ & $4 / 3$ \\
Rectosigmoid & $1(8)$ & $1 / 0$ & $1 / 0$ \\
Sigmoid & $1(8)$ & $0 / 1$ & $1 / 0$ \\
Transverse & $1(8)$ & $0 / 1$ & $1 / 0$ \\
Ascending & $2(15)$ & $1 / 1$ & $1 / 1$ \\
Descending & $1(8)$ & $1 / 0$ & $1 / 0$ \\
\hline
\end{tabular}

GWT in 36 patients based on CT images. Endoscopy revealed a total of 38 lesions in their study, including 2 concurrent lesions in 2 patients. Nineteen lesions (50\%) were gastritis, $4(10.5 \%)$ were hiatal hernia, 3 were $(7.9 \%)$ benign ulcers, 3 (7.9\%) were benign neoplasms, 8 (21\%) were malignant neoplasms, and the upper GIS endoscopy revealed no abnormality in one patient $(2.6 \%)$. In this study, we observed similar results.

In a study in 2004, 154 patients who underwent endoscopy after a determination of wall thickness on CT were examined by Tongdee et al. ${ }^{5}$ While $22(14.2 \%)$ had a malignancy, $66(42.8 \%)$ had benign conditions or normal endoscopy findings.

In a study conducted in 2002, Cereceda Pérez et a ${ }^{10}$ performed endoscopy for 92 patients due to the wall thickness observed incidentally on CT. In 12 patients (13\%), normal findings were documented using CT and endoscopy. Of the 80 pathological cases, benign results were found for $29(31.5 \%)$ and malignant results were found for 51 (55.4\%). In our research, gastric and colonic wall thickening was detected incidentally. The malignancy rate was lower than that observed by Cereceda Pérez et al, which may be a reflection of the prompt for examination in their study.

Tellez-Avila et a ${ }^{11}$ found gastric cancer in 6 of 31 patients with increased GWT detected on CT. Urban et al ${ }^{12}$ observed that GWT increased in gastritis associated with Helicobacter pylori. However, in 2008, Kul et $\mathrm{al}^{13}$ reported that $H$. pylori-positive patients did not display significant GWT compared with $H$. pylori-negative patients. We did not find a significant relationship between $H$. pylori positivity and GWT.

In 1995, a study of increased colon wall thickness detected incidentally on CT was published by Rockey 
et al. $^{14}$ Colonoscopy revealed an important pathology in approximately $67 \%$. Similarly, in a study conducted by Moraitis et $\mathrm{al}^{15}$ in 2006, 40 patients had increased intestinal wall thickness and colonic neoplasia was detected in $23 \%$. The authors recommended the use of colonoscopy for further evaluation of incidental findings of colonic thickening, though it may be a result of the original disease presentation.

Another retrospective study was published by Eskaros et al. ${ }^{16}$ They reported a $64 \%$ correlation between increased intestinal wall thickness seen on CT and abnormal colonoscopy results. The most common reason for a colonoscopy in their study was nonspecific colitis.

Wolff et $\mathrm{al}^{17}$ evaluated 107 patients who presented with abdominal pain in a US teaching hospital. While 26\% had routine colonoscopy findings, they reported that inflammatory bowel disease was found in $9.3 \%$, ischemic colitis in $36.4 \%$, infectious colitis in $15 \%$, and cancer in $7.4 \%$. Very few of these patients had other endoscopic findings.

The primary limitation of our study is the small number of patients evaluated, particularly regarding those who underwent colonoscopy. Colonoscopy examination is typically used to assess the possibility of colon pathologies. Our focus was on incidental findings. Although small intestine wall thickness was frequently seen in imaging, these patients were excluded from the study because CT enteroscopy and magnetic resonance enteroscopy were not available in our hospital.

In our study, malignancy was frequently detected in the antrum and cardioesophageal junction in the upper gastrointestinal tract. Malignancy was detected in 50\% of the patients with increased wall thickness observed on CT in the cardioesophageal region. The incidence was significantly higher when compared with the antrum $(P=0.020)$.

Detection of above-average wall thickening in the gastrointestinal tract with imaging methods before finding pathologies endoscopically can reflect differences between health facilities, such as the quality of the radiographic procedure, the use of a contrast agent, and the experience of the physician evaluating the results.

In conclusion, our results indicated that findings of increased GWT on CT were helpful in the diagnosis of a gastrointestinal pathology and provided guidance for diagnostic and treatment management plans. Since the increase in wall thickness detected on an abdominal CT taken for nonspecific symptoms cannot precisely exclude a pathology, we recommend an endoscopic evaluation to determine the underlying cause and to better direct patient care.

\section{Authors' Contribution}

ES, YK, and MUK: Study concept and design. ES, ÜT, SS, EB, AO, CB, CO, and YET: Acquisition, analysis, or interpretation of data. ES, YK, and EB: Statistical analysis. ES, and YK: Drafting of the manuscript. ES, YK, and MUK: Critical revision of the manuscript for important intellectual content.

\section{Conflict of Interest Disclosures}

All authors declare that they have no conflict of interest.

\section{Ethical Statement}

This study received approval from the Kanuni Sultan Suleyman Training and Research Hospital local ethics committee (review board number: 2020.07.141).

\section{Funding}

None.

\section{References}

1. Kumar A, Rana SS, Nada R, Kalra N, Sharma RK, Dutta U, et al. Significance of ileal and/or cecal wall thickening on abdominal computed tomography in a tropical country. JGH Open. 2018;3(1):46-51. doi: 10.1002/jgh3.12103.

2. Kim JY, Kim SH, Lee JM, Han JK, Lee JY, Choi Bl. Differentiating malignant from benign wall thickening in postoperative stomach using helical computed tomography: results of multivariate analysis. J Comput Assist Tomogr. 2007;31(3):45562. doi: 10.1097/01.rct.0000243454.15684.e2.

3. Al-Khowaiter SS, Brahmania M, Kim E, Madden M, Harris A, Yoshida EM, et al. Clinical and endoscopic significance of bowel-wall thickening reported on abdominal computed tomographies in symptomatic patients with no history of gastrointestinal disease. Can Assoc Radiol J. 2014;65(1):6770. doi: 10.1016/j.carj.2012.01.002.

4. Baș B, Pakoz ZB, Oymacı E. Endoscopic evaluation of patients with gastric wall thickening detected with computed tomography. Laparosc Endosc Surg Sci. 2019;26(1):1-4. doi: 10.14744/less.2019.64436.

5. Tongdee R, Kongkaw L, Tongdee T. A study of wall thickness of gastric antrum: comparison among normal, benign and malignant gastric conditions on MDCT scan. J Med Assoc Thai. 2012;95(11):1441-8.

6. Troppmann M, Lippert E, Hamer OW, Kirchner G, Endlicher E. Colonic bowel wall thickening: Is there a need for endoscopic evaluation?. Int J Colorectal Dis. 2012;27(5):601-4. doi: 10.1007/s00384-011-1362-x.

7. Karim MS, Miranda MC, Shamma'a JM, Goebel SU, Sundaram U. Utility of upper endoscopy and colonoscopy in evaluating gastrointestinal luminal wall thickening found on computed tomography. WV Med J. 2010;106(7):16-9.

8. Ba-Ssalamah A, Prokop M, Uffmann M, Pokieser P, Teleky B, Lechner G. Dedicated multidetector CT of the stomach: spectrum of diseases. Radiographics. 2003;23(3):625-44. doi: 10.1148/rg.233025127.

9. Insko EK, Levine MS, Birnbaum BA, Jacobs JE. Benign and malignant lesions of the stomach: evaluation of CT criteria for differentiation. Radiology. 2003;228(1):166-71. doi: 10.1148/ radiol.2281020623.

10. Cereceda Pérez CN, Urbasos Pascual MI, Romero Castellanos C, Carreira Gómez C, Pinto Varela JM. Helical CT of the stomach: differentiation between benign and malignant pathologies, together with the staging of gastric carcinoma. Rev Esp Enferm Dig. 2002;94(10):601-12.

11. Tellez-Avila Fl, García-Osogobio S, Chavez-Tapia NC, Ramirez-Luna MA, Franco-Guzman A, Sosa-Lozano A, et al. Utility of endoscopy in patients with incidental gastrointestinal 
luminal wall thickening detected with CT. Surg Endosc. 2009;23(10):2191-6. doi: 10.1007/s00464-008-0274-5.

12. Urban BA, Fishman EK, Hruban RH. Helicobacter pylori gastritis mimicking gastric carcinoma at CT evaluation. Radiology. 1991;179(3):689-91. doi: 10.1148/radiology.179.3.1888360.

13. Kul S, Sert B, Sari A, Arslan M, Koşucu P, Ahmetoğlu A, et al. Effect of subclinical Helicobacter pylori infection on gastric wall thickness: multislice CT evaluation. Diagn Interv Radiol. 2008;14(3):138-42.

14. Rockey DC, Halvorsen RA Jr, Higgins JL, Cello JP. Prospective evaluation of patients with bowel wall thickening. Am J Gastroenterol. 1995;90(1):99-103.

15. Moraitis D, Singh P, Jayadevan R, Cayten CG. Colonic wall thickening on computed tomography scan and clinical correlation. Does it suggest the presence of an underlying neoplasia?. Am Surg. 2006;72(3):269-71.

16. Eskaros S, Ghevariya V, Diamond I, Anand S. Correlation of incidental colorectal wall thickening at CT compared to colonoscopy. Emerg Radiol. 2009;16(6):473-6. doi: 10.1007/ s10140-009-0806-x.

17. Wolff $J \mathrm{H}$, Rubin A, Potter JD, Lattimore W, Resnick MB, Murphy BL, et al. Clinical significance of colonoscopic findings associated with colonic thickening on computed tomography: is colonoscopy warranted when thickening is detected?. J Clin Gastroenterol. 2008;42(5):472-5. doi: 10.1097/MCG.0b013e31804c7065. 